\title{
Study on the Applications of FBG Technology in River Level Monitoring
}

\author{
Tan Dongjie \\ College of Mechanical and Transportation Engineering \\ China University of Petroleum \\ Beijing, China \\ e-mail: tdj@petrochina.com.cn
}

\author{
Wang Baoyan \\ ChangQing Oil\&Gas Transportation Sub-Company \\ PetroChina Pipeline Company \\ Yinchuan, China \\ e-mail: wangbaoyan0115@petrochina.com.cn
}

\author{
Han Bing \\ Pipeline R\&D Center \\ PetroChina Pipeline Company \\ Langfang, China \\ e-mail: kjhanbing@.petrochina.com.cn \\ Li liangliang \\ Pipeline R\&D Center \\ PetroChina Pipeline Company \\ Langfang, China \\ e-mail: kjlill@.petrochina.com.cn
}

\begin{abstract}
In order to overcome the disadvantage of low accuracy for traditional monitoring technologies of river level, and solve the problems in real-time data acquisition and remote transmission for the existing hydrological observation, we design a new monitoring system of river level based on fiber grating technology, which can realize high sensitivity and automatic monitoring of river level. The system has been put into practical application in a monitoring project and the measurement results indicate that this system is of such advantages as real-time capability, high accuracy, unattended operation, and can well meet the present requirements of hydrological observation and measurement.
\end{abstract}

Keywords-FBG; sensing technology; river level; GPRS; remote monitoring

\section{INTRODUCTION}

As one of the basic hydrological elements of indicating for flood situation of river or reservoir area, water level is an important part of hydrological regime and one of the basic items of hydrology testing, and it is also an important parameter of the dam project, irrigation and drainage, flood discharge, flood control decision and flood prediction. The existing measurement methods of water level adopt a variety of sensor technologies, such as the float type, piezoresistive type, or bubble type fluviograph and electronic staff gauge and etc.; although these traditional monitoring ways can achieve water level measurement, they all have some limitations in different extents, such as low measurement precision, high power consumption, poor anti-interference capacity, easy to aging or corrosion, difficult to extend, inconvenience of installation and maintenance and so on. For some contactless fluviographs, such as radar type, laser type or acoustic type, which are characterized by high measurement precision, but they are costly and have high requirements of equipment installation, and the measurement range is limited by detection angles, resulting in the higher false positive rate and the regular calibration is needed.

Fiber Bragg grating (FBG) is a new type of optical fiber passive device, which is formed by creating periodical distribution of refraction index in fiber core based on the photosensitive characteristics of fiber material, and it has the advantages of anti-electromagnetic interference, waterproof, wide dynamic range, high sensitivity, convenient to build up network and easy to realize distributed measurement. It is reported that there are a variety of quantities can be measured by using FBG sensing technology, such as temperature, strain, pressure, stress, acceleration, vibration, torque, and etc. In this article, we have designed a set of automatic device for river level monitoring based on FBG sensing technology, which has the characteristics of high measurement accuracy, stability and reliability. In order to satisfy real-time requirement, we have applied the GPRS technology to the communication between field monitoring station and remote monitoring terminal.

\section{STRUCTURE AND PRINCIPLE OF FBG FLUVIOGRAPH}

\section{A. Principle of FBG sensing}

FBG is the simplest and most widely used fiber grating, it is an optical fiber which the refractive index varies periodically, and the modulation depth of refractive index and grating period are generally constant. The changes in temperature or strain can cause the changes in period and refractive index of FBG, and then lead to the changes in reflection spectrum and transmission spectrum of FBG. We can obtain the variation values of temperature and strain by detecting reflection spectrum and transmission spectrum of FBG. When the ambient temperature, strain, or other physical quantities change, the grating period $\Lambda$ or fiber core refractive index $n_{\text {eff }}$ will change, and the reflection spectrum and transmission spectrum of FBG will change as well, which will cause the center wavelength of the fiber grating to occur a displacement $\Delta \lambda$, as shown in Figure 1. 

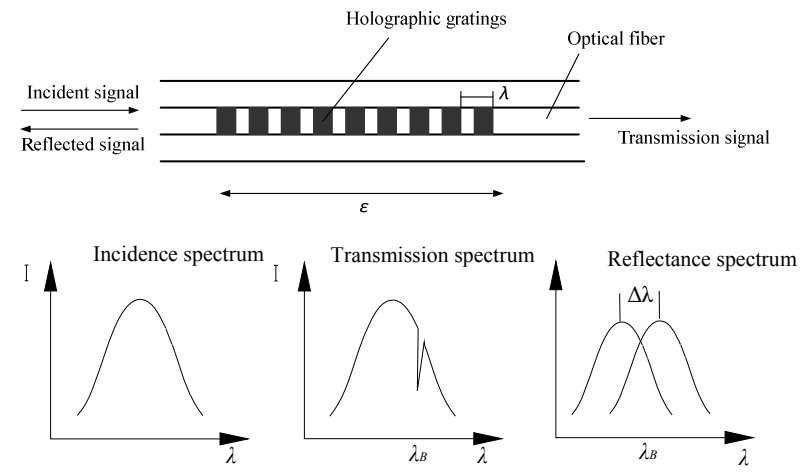

Figure 1. Schematic diagram of FBG sensing principle.

Based on the coupled mode theory, a guided mode which is propagated in uniform FBG may be coupled to another one propagated in the opposite direction to form a narrowband reflection, and the peak reflection wavelength $\lambda_{B}$ can be written as follow

$$
\lambda_{B}=2 n_{e f f} \Lambda
$$

Where, $\lambda_{B}$ is Bragg wavelength, $n_{\text {eff }}$ is effective refractive index of fiber transmission mode, $\Lambda$ is grating pitch.

We can get wavelength shift of FBG, $\lambda_{B}$, which is caused by strain $\varepsilon$ and temperature difference $\Delta T$ by differential transformation with respect to Eqs. (1), as follow

$$
\frac{\Delta \lambda_{B}}{\lambda_{B}}=\left(\alpha_{f}+\xi\right) \Delta T+\left(1-P_{e}\right) \varepsilon
$$

Where, $\alpha_{f}, \zeta$ and $P_{e}$ are the thermal expansion coefficient, thermo-optical coefficient and elasto-optical coefficient of fiber optic materials.

\section{B. Design of FBG fluviograph}

The constitution of FBG fluviograph is shown in figure 2, its main body is an airtight waterproof box with a thin-wall steel tube inside it, and there are three fiber grating strain sensors with function of temperature compensation, FBG1, FBG2 and FBG3, are adhered to the monitoring crosssection of steel tube at the interval of 90 degrees; the FBG sensors are connected in series by fusion welding and accessed into the fiber junction box with optical cable.

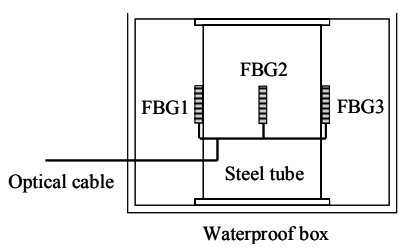

a) The profile drawing

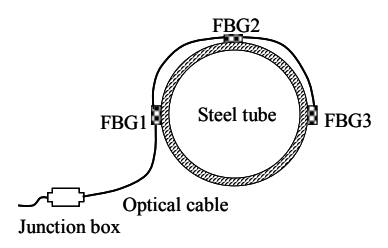

b) The cross-section drawn
Figure 2. Diagrammatic drawing of FBG fluviograph.
According to hydrostatics, the hydro-static pressure $P$ at a depth of $h$, can be written as follow

$$
P=P_{0}+\not h \text {. }
$$

Where $P_{0}$ is the atmospheric pressure, $\gamma$ is the unit weight of water. The hydro-static pressure $P$ will change in the case of water level change. The deformation will occur on waterproof box due to the change of hydro-static pressure $P$, which leads to the thin-wall steel tube fixed in box producing axial strain. Based on theory of elastic mechanics, we have

$$
P=E \varepsilon_{m}
$$

Where $E$ is the elastic modulus of thin-wall steel tube, $\varepsilon_{m}$ is the mean strain on monitoring cross-section of steel tube, which can be solved with three-point method as shown in Figure 3.

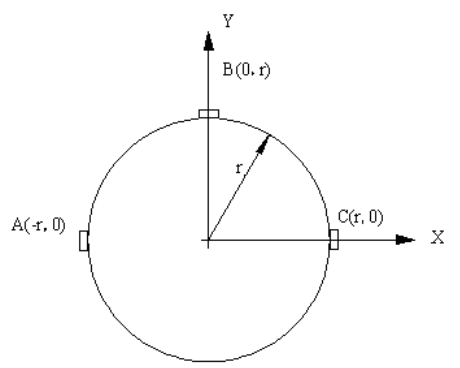

Figure 3. Geometric schematic diagram of three-point method.

We can define the axial strains on any cross-section of steel tube by the following formula,

$$
m x+n y+p z=1 \text {. }
$$

Where, $x$ and $y$ are the coordinates of any point in crosssection, $z$ is the axial strain of point $(x, y), m, n$ and $p$ are arbitrary constants, and the strain $z$ can be deduced from three known strains, $A, B$ and $C$, which are obtained based on the measurement results from three FBG sensors, so we have

$$
z=\frac{A+C}{2}+\left(\frac{C-A}{2}\right)\left(\frac{x}{r}\right)-\left(\frac{A+C-2 B}{2}\right)\left(\frac{y}{r}\right)
$$

In view of the symmetry of strains in respect of $X$ axis, we have taken the derivative of $x$ with respect to Eqs. (6) and can get the maximum or minimum strain, and then obtain the coordinates of $(x, y)$ corresponding to the maximum or minimum strain by making the value is equal to zero. By the derivation of formula, we have

$$
\frac{x}{r}=\frac{C-A}{\sqrt{2 A^{2}+2 C^{2}+4 B^{2}-4 A B-4 B C}} .
$$




$$
\frac{y}{r}= \pm \sqrt{1-\left(\frac{x}{r}\right)^{2}}
$$

Combining Eqs. (6) Eqs. (8), we can get the maximum strain $z_{\max }$ and minimum strain $z_{\min }$ on monitoring crosssection of steel tube, taking the average of both them, $\varepsilon_{m}$, as the mean strain on monitoring cross-section, as follow

$$
\varepsilon_{m}=\frac{z_{\max }+z_{\min }}{2} .
$$

Combining Eqs. (6) Eqs. (9), we have

$$
\varepsilon_{m}=(A+C-2 B) \sqrt{\frac{A^{2}+4 B^{2}+C^{2}+2 A C-4 A B-4 B C}{2 A^{2}+4 B^{2}+2 C^{2}-4 A B-4 B C}} .
$$

After substitution of Eqs. (3) and Eqs. (4) into Eqs. (10), we have

$$
h=\frac{(A+C-2 B) E \sqrt{\frac{A^{2}+4 B^{2}+C^{2}+2 A C-4 A B-4 B C}{2 A^{2}+4 B^{2}+2 C^{2}-4 A B-4 B C}}-P_{0}}{\gamma}
$$

Based on Eqs. (11), the river level $h$ can be obtained indirectly by using the FBG fluviograph.

\section{DESIGN OF MONITORING SYSTEM}

\section{A. Hardware structure of system}

In order to achieve the remote and real-time monitoring of river level, we have built the monitoring system based on the FBG fluviograph and GPRS wireless communication technology, which mainly includes two major parts, one is the field monitoring station, the other is the remote surveillance center. The field monitoring station consists of the FBG fluviograph, which is fixed in river bed with a embedded pile, FBG demodulator, lower computer, GPRS module and solar power supply device, and the lower machine is connected with GPRS module via RS-232 serial port; the remote surveillance center consists of the GPRS module and upper computer, and they are connected to each other via RS-232 serial port. The hardware structure diagram of monitoring system is shown in Figure 4.

\section{B. Software component of system}

The software component of system mainly includes data acquisition, storage, transmission, reception, analysis processing, results display and giving an alarm functions, the software process of system is shown in Figure 5. After the start of the system, the upper computer will send a data request to the field monitoring station; the lower computer will give notice to the FBG fluviograph for data acquisition after it has received this command, the FBG demodulator will demodulate the preliminary data and send them to the lower computer; the lower computer will convert the strains of FBG sensors into the river level with the built-in algorithm given by Eqs. (11); the GPRS module will send the preprocessing results of monitoring data to the remote surveillance center through wireless communication network; the upper computer will process the received data and display the real-time variations of river level; when the threshold of river level has been reached, the system will give an alarm signal.

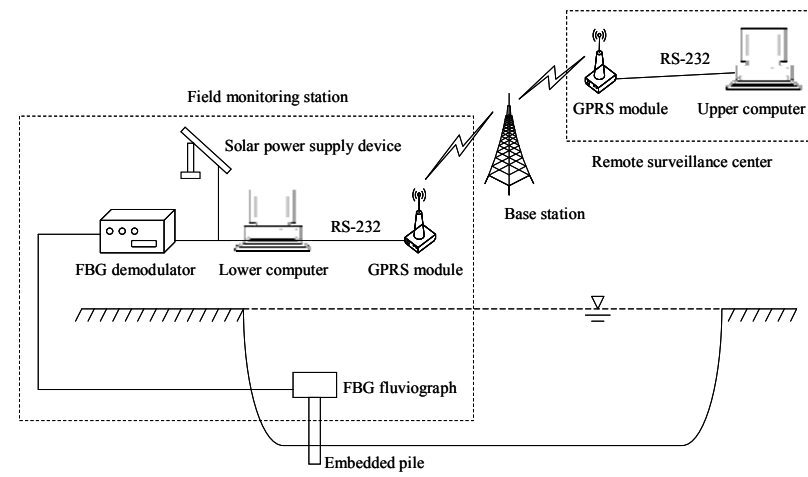

Figure 4. Structure diagram of the monitoring system.

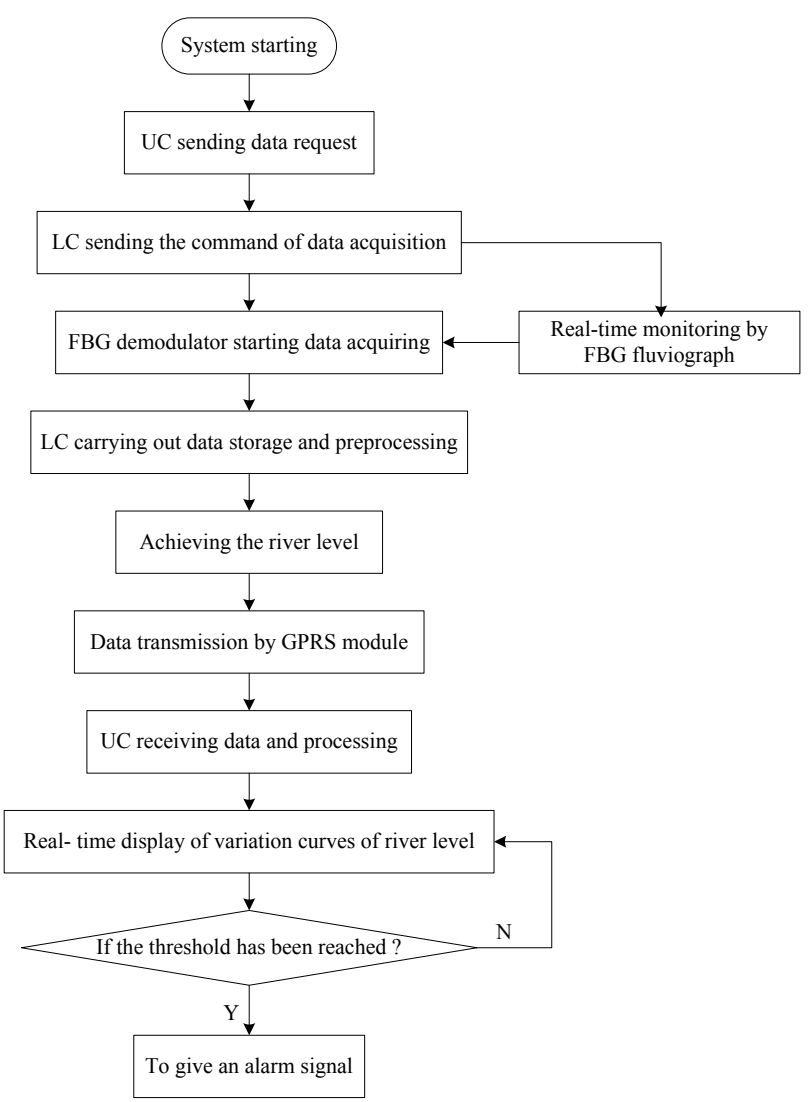

Figure 5. Software process of the monitoring system. 


\section{PRACTICAL EXAMPLE}

In order to test the monitoring system, field experiments were carried out by using two kinds of monitoring devices of river level, the float type and FBG fluviographs, in Langping River Valley of Changyang County, Yichang City, Hubei Province, in central China. This river is a typical mountainous seasonal stream, and the changes of river level during the low water period and flood season are obvious. Figure 6 shows the monitoring results of river level during three days of persistent rain. As can be seen from the figure, the river level obtained from the FBG fluviograph are well agreed with the ones based on the float fluviograph.

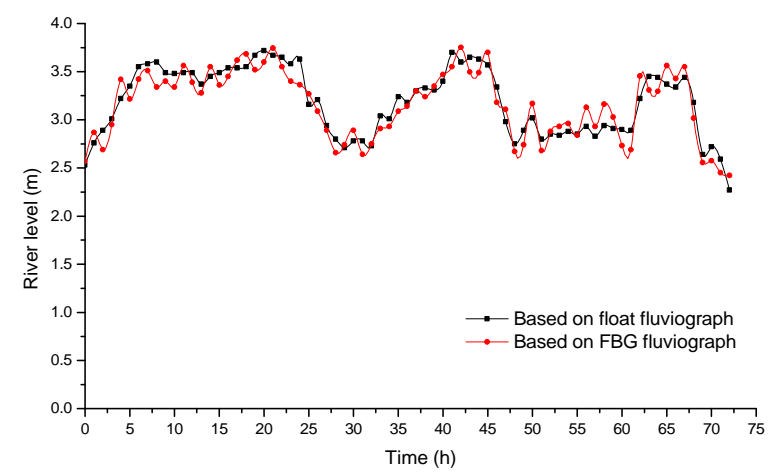

Figure 6. Curves of river level during three days of persistent rain.

\section{CONCLUSIONS}

In this article, a new type of FBG monitoring device for river level is designed by introducing the fiber grating sensing technology into the hydrological measurement field, which has the advantages of high measuring accuracy, electromagnetic interference resistance, corrosion resistance and other characteristics. Based on the FBG fluviograph, we have built a real-time and remote monitoring system and carried out the field experiment on a river in central China. The experiment results indicate that the FBG fluviograph is characterized by low power consumption, high reliability, unattended operation and uninterrupted measurement, which can reduce the monitoring costs, improve the monitoring efficiency, and it has a promising future in engineering application.

\section{ACKNOWLEDGMENT}

This work was supported by the National Natural Science Foundation of China (Grant No. 50774090).

\section{REFERENCES}

[1] K. O. Hill, G.Meltz, "Fiber bragg grating technology fundamental and overview," J Lightware Technol, vol. 15, No. 8, pp. 1263-1276, 1997.

[2] V. E. Sakharov, S. A. Kuznetsov, and B. D. Zaitsev, "Liquid level sensor using ultrasonic lamb waves," Ultrasonics, vol. 41, pp. 319322, 2003.

[3] P. Raatikainen, I. Kassamakov, and R. Kakanakov, "Fiber-optics liquid-level sensor," Sensors and Actuator A, vol. 58, No.9, pp. 93-97, 1997.

[4] T. W. MacDougall, S. Pilevar, and C. W. Haggans, "Generalized expression for the growth of long period gratings," IEEE Photonics Technology Letters, vol. 10, No. 10, pp. 1449-1451, 1998.

[5] S. Khaliq, S. W. James, and R. P. Tatam, "Fiber-optic liquid-level sensor using a long-period grating," Opt. Lett., vol. 26, No. 16, pp. 1224-1226, 2001.

[6] H. Golnabi, "Design and operation of a fiber optic sensor for liquid level detection," Optics and Lasers in Engineering, vol. 41, pp. 801812, 2004.

[7] X. F. Dong, Y. L. Huang, and X. G. Gu, "A novel method for fiber grating vibration sensor," Piezoelectrics \& Acoustooptics, vol. 26, No. 5 , pp. 357-359, 2004

[8] S. H. Chung, J. H. Kim, and B. A. Yu, "A fiber bragg grating sensor demodulation technique using a polarization maintaing fiber loop mirror," IEEE Photo Tech. Lett, vol. 13, No. 12, pp. 1343-1345, 2001.

[9] S. H. Kim, J. J. Lee, and D. C. Lee, "A study on the development of transmitsion-Type Extrinsic Fabry-Perot interferometric optical fiber sensor,” J. Lightwave Technol., vol. 17, No. 10, pp. 1869-1874, 1999.

[10] E. Musayev, S. E. Karlik, "A novel liquid level detection method and its implementation,” Optik, vol. 117, pp. 95-100, 2006.

[11] M. Borecki, J. Kruszewski, and K. Kopczynski, "Concepts of fibre optic intensity sensor liquid level measurement," Opt. Appl., vol. 30, pp. 141-150, 2000.

[12] Y. F. Yang, Y. X. Sun, and C. S. Sun, "Liquid-level Measurement with Fiber-optic Low Coherence Interferometer: Micrometerresolution Approach," Semiconductor Photonics and Technology, vol. 13, No. 2, pp. 108-111, 2007. 